\title{
Event-related potential investigation of different neural pathways for face and pattern perceptions in the human brain
}

\author{
Ryozo Aoki $^{1}$, Shinnya Okamoto ${ }^{2}$, Takahiro Sakimoto $^{2}$, Kazuki Yoshida ${ }^{2}$ Hitoshi Sasaki $^{1}$ \\ ${ }^{1}$ Department of Physiology, Graduate School of Medicine, Osaka University, Suita, Japan \\ ${ }^{2}$ Department of Electricity and Electronics, College of Industrial Technology, Amagasaki, Japan \\ Email: ryo-aoki@kcc.zaq.ne.jp
}

Received 26 January 2012; revised 24 February 2012; accepted 6 March 2012

\begin{abstract}
Two different pathways in the brain have been implicated in the human visual perception process. One involves emotional cognition of face features, and the other involves spatial pattern cognition. In the present study, we used the event-related potential (ERP) method to examine temporal activation of the perception pathways at a fine time resolution of less than $\mathbf{1 0}$ ms. Four electrodes were attached onto their heads at $O_{2}, P_{z}, T_{4}$, and $F_{z}$, and ERP waveforms were observed on each electrode simultaneously. Nine portraits of actresses and 9 geometrical figures were chosen respectively, and presented on a CRT display in random order. The two types of figures elicited different responses. For portraits, the first significant N100 peak appeared on $P_{z}$ and $F_{z}$, but not $O_{2}$. For patterns, it started at $\mathrm{N130}$ on $\mathrm{O}_{2}$. A significant response to portraits mostly appeared on $T_{4}, P_{z}$, and $F_{z}$, and to patterns on $\mathrm{O}_{2}, \mathbf{P}_{\mathrm{z}}$, and $\mathrm{F}_{\mathrm{z}}$.
\end{abstract}

Keywords: Influenza Visual-Perception; Cognition-System; Limbic-System; Oddball-Method; ERP; N100; N170; P300

\section{INTRODUCTION}

For most human and non-human primates, face perception of other animals is essential for escaping from or attacking them. A core brain system associated with face recognition has been described [1,2] that involves two components $[3,4]$. The first, comprising the static figure analysis of shape, color, numbers, and facial patterns, involves the fusiform gyrus of the ventral or temporal association cortex, and the second, perception of motion in features, involves the parietal sulcus of the dorsal association cortex.

Even limited to the static case, the visual cognition system has been investigated systematically to identify various parts of the brain that participate in the instantaneous recognition of face patterns and features, revealing two distinct pathways for visual perception. One pathway particularly emphasizes features of facial emotion; it originates from the retina and proceeds to the pulvinar nucleus of the thalamus, then the amygdala, and finally the inferotemporal cortex $[5,6]$. The other pathway is necessary for pattern recognition, and it originates from the retina and proceeds to the occipital visual cortex, then the posterior parietal association cortex, and finally the fusiform gyrus. Additionally, this image information is compared with a stored image from the hippocampus or amygdala in the limbic system, which had been adopted in the Papez-Yakovlev circle [7] and recognized in the visual cortex [8]. Finally, both pathways are joined in the orbito-frontal association cortex and proceed to the visual sensory association cortex.

Recently these various brain areas and pathways have been investigated with fMRI and PET [3,9]. Most of these investigational procedures are based on blood density flowing to the organ, which limits time resolution to a minimum of $0.5 \mathrm{~s}$ [10] and prevents the acquisition of information concerning the temporal sequence of brain area activity throughout the pathway.

In contrast, the event-related potential (ERP) method is based on the spontaneous emission of the electrostatic potential waves induced by the neuronal activations due to event related sensory stimulation, and it possesses fine time resolution of less than $10 \mathrm{~ms}$ [11]. However, drawbacks to the method include the traditional limitation of the fine-grained spacial resolution of ERPs, and the overlapping of ERP waveforms, which can make analysis difficult [10].

ERP has already been systematically applied to the investigation of the components of brain activities [9,12] such as cognitive processing, by circumscribing specific stages of the distinguish, for example the N170 component of face perception [13]. 
Accordingly, we applied ERP to the present analysis of this perception process.

Here, different activation patterns were observed in response to different types of visual stimuli, supporting the existence of two different pathways in visual perception as discussed above.

\section{EXPERIMENTAL METHODS}

\subsection{Participants}

A total of 10 healthy subjects (20 to 24 years old male students) were involved in this study, and nine of them participated in the ERP experiment. They were all righthanded, and had normal vision with or without glasses, and they gave written informed consent about the experimental procedure and approved by the College committee.

\subsection{Apparatus and Stimuli}

In the present study the ERP wave forms were simultaneously observed on 4 channels using a signal processor (NEC Synax-2100, Tokyo). The band-pass filter was set at a frequency of $0.5-100 \mathrm{~Hz}$.

Each subject was laid on a bed covered with a grounded conductive sheet for use of noise reduction in an electromagnetically shielded room, in which without any introduction of AC power lines and covered with a metal mesh wall, through which windows are set for light illumination and for video picture display to the participant.

All the signal wires from the electrodes were extruded from the room through a metal tube and led to respective pre-amplifier outside.

As the stimuli, facial features and geometrical patterns were adopted for comparison.

Nine portraits of actress [14] and 9 geometrical patterns were adopted as shown in Figures 1(a) and (b).

\subsection{Experimental Procedures}

For the ERP observations, $\mathrm{Ag} / \mathrm{AgCl}$ electrodes were attached onto each subjects' head at sites near the occipital visual cortex $\left(\mathrm{O}_{2}\right)$, temporal cortex and amygdale $\left(\mathrm{T}_{4}\right)$, posterior parietal cortex $\left(\mathrm{P}_{\mathrm{z}}\right)$ and frontal and sensory association cortex $\left(F_{z}\right)$, and also the reference potential electrode at the linked ear lobes. Before attaching the electrodes, the skin of the head was rinsed with alcohol and polished with abrasive until a contact resistance of less than $5 \mathrm{k}$ ohm was attained, then it permitted us observation of fine ERP waveforms.

\subsection{ERP Recording and Data Analysis}

The figures of portrait and pattern were presented in a series respectively on the CRT display in random order that was determined by a statistical random number table in the computer. After the display start at $0 \mathrm{~ms}$, the time development of ERP was recorded simultaneously by the 4 electrodes at $\mathrm{O}_{2}, \mathrm{~T}_{4}, \mathrm{~F}_{\mathrm{z}}$ and $\mathrm{P}_{\mathrm{z}}$.

The display was continued $0.5 \mathrm{sec}$ and after an interval of $1 \mathrm{sec}$, and it was succeeded 50 times which time schedule is presented in Figure 1(c).

The evoked ERP waveform was recorded and integrated for the 50 times repetition by the signal processor, and it is shown in Figure 2.

The oddball method was adopted by instructing subjects to push a button (un-connected to a circuit, but having an enhancement effect on the mental cognition) when a pre-indicated figure (which was first selected by the subject as favorite) was realized and it was recorded as indicated (I) in Figure 2. There after the indication was changed by announcement to another figure, but the recording was continued unchanged, and the data from the same figure was recorded as un-indicated (U) as shown in Figure 3.

The time schedule of those observations is summarized in Figure 1(c).

These ERP data were obtained almost reproducibly for a long time repetition of the visual stimuli, in the course of indicated and un-indicated. Accordingly, about 1.5 hour continuous operation was adopted as routine, including 50 times sampling both of the indicated and unindicated cases and then 4 trials of the portrait and pattern sequence presentations as depicted in Figure 1(c).

\section{RESULTS}

The observed ERP data from 3 participants showed clear and similar "indicated" waveforms which were ascertained further several times examinations in later days.

However data from another 4 participants were partly unclear in some peaks. Data from the remaining 2 subjects were obscure, probably due to insufficient attention directed to the indicated display, as evidenced by their similar responses in the "indicated" and "un-indicated" conditions. Accordingly, we adopted the clear data for further analysis, as shown in Figures 2 and 3. Data averaging among the different participants makes the waveform round and fine peak structures are smeared out. As a result, a typical individual clear waveform is adopted in Figures 2 and 3.

In Figure 2, observed ERP waveforms on 4 electrodes at $\mathrm{O}_{2}, \mathrm{~T}_{4}, \mathrm{~F}_{\mathrm{z}}$, and $\mathrm{P}_{\mathrm{z}}$ are shown in time $\mathrm{t}(\mathrm{ms})$, where the oddball method upon presentation is applied and the indicated figure (I) and the un-indicated (U), for either the case of face (F, red line) and pattern (G, blue line) at (I). Also in Figure 3, data of the un-indicated (U) are presented for face (F, orange line) and the pattern (G, green lines). 


\section{0}
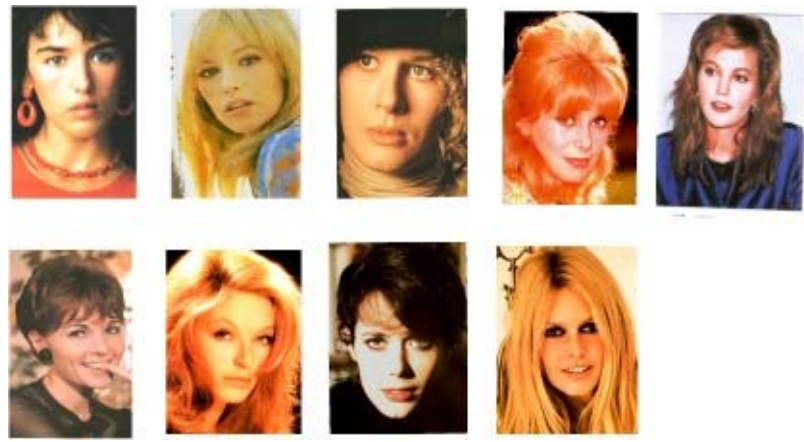

(a)
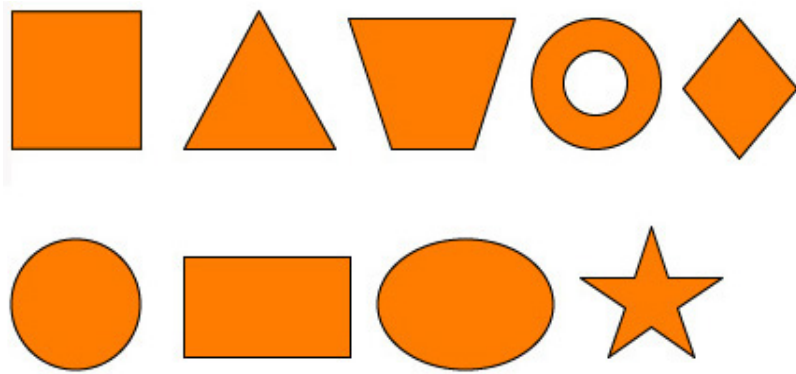

(b)

ERP observations for each 9 participants

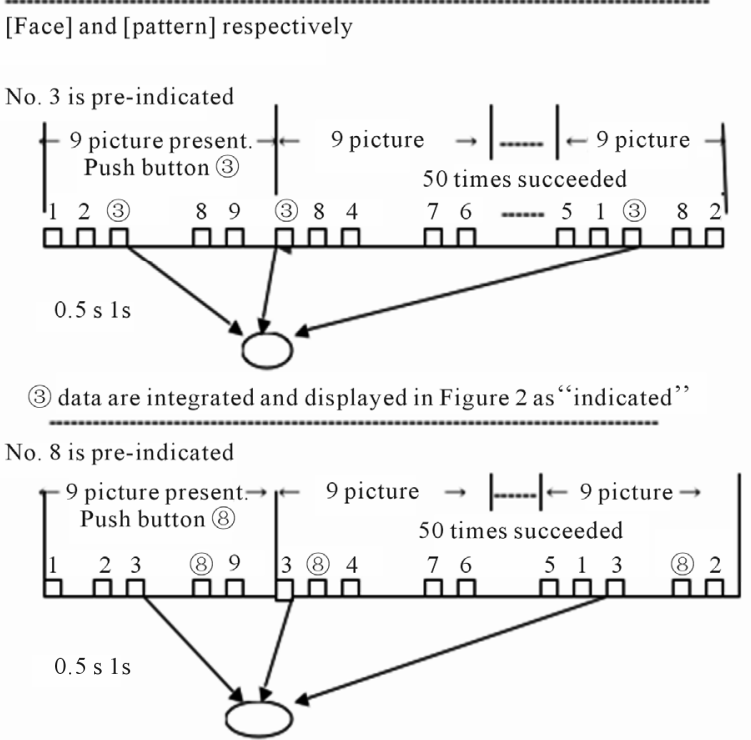

No. 3 data are still integrated and displayed in Figure 3 as "un-indicated"

Further 4 times of the same sequence are repeated in total 1.5 hours

More several times reconfirmation is carried in other days.

(c)

Figure 1. Figures presented to the participants and its sequence in the experiment: (a) 9 portraits of actresses' faces (F); (b) 9 geometrical patterns (G); (c) Time sequence of the ERP observations. Here in both cases, data on (3) are really sampled, and in the former case (3) is pre-indicated by announcement, but in the latter case (8) is announced, for data of the non-indicated.

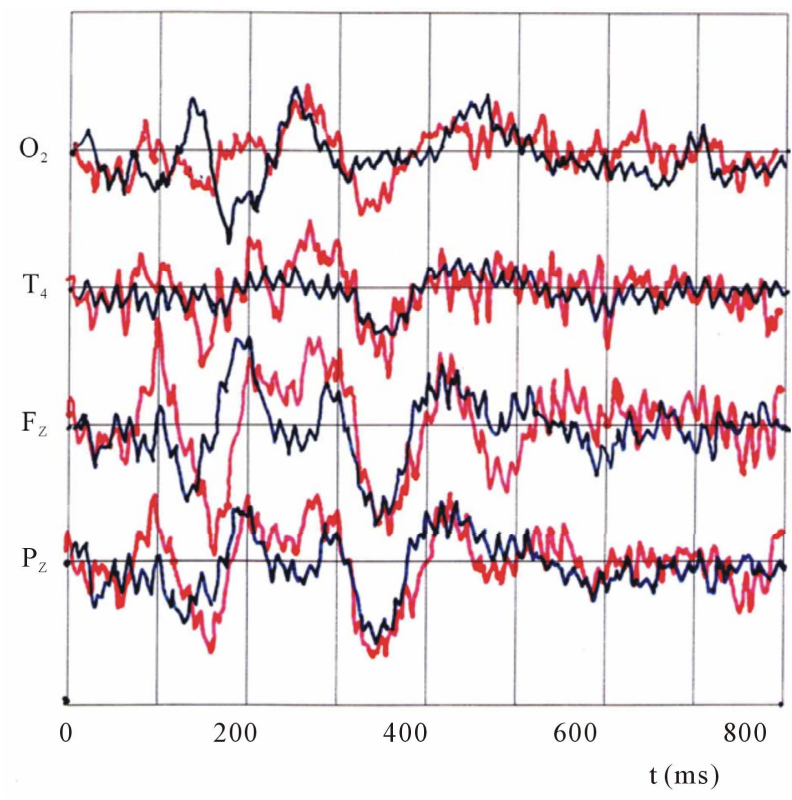

Figure 2. Observed ERP waveforms on 4 electrodes at $\mathrm{O}_{2}, \mathrm{~T}_{4}$, $\mathrm{F}_{\mathrm{z}}$, and $\mathrm{P}_{\mathrm{z}}$ as a factor of time (ms), for the pre-indicated figure (I) in the oddball method, on either a face (F, red line) or pattern ( $\mathrm{G}$, blue line).

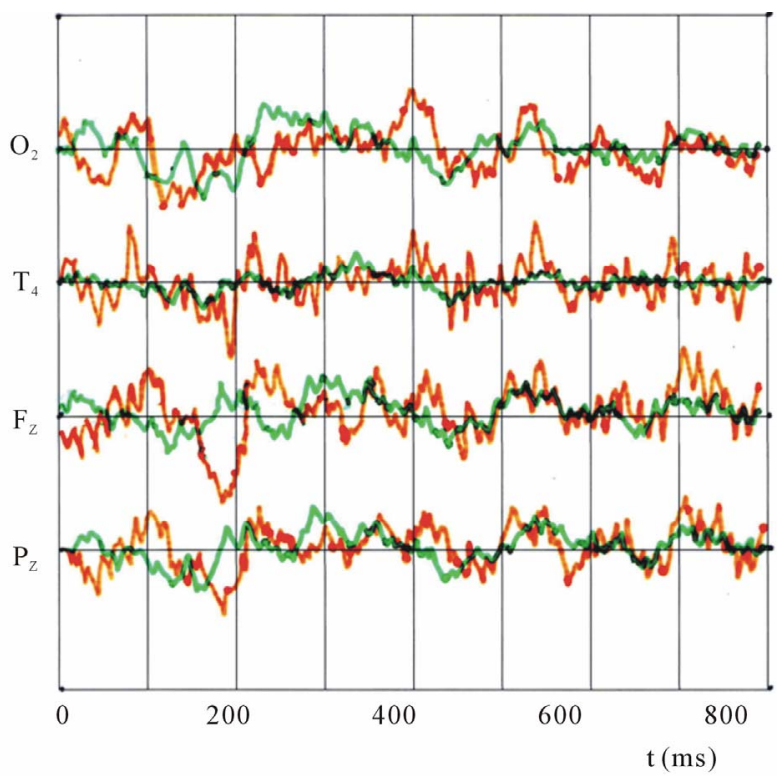

Figure 3. Observed ERP waveforms on 4 electrodes using the oddball method upon presentation of the unindicated figure (U), which was either a face ( $F$, orange line) or a pattern $(\mathrm{G}$, green line).

As the result, different activation patterns were observed in response to different types of visual stimuli. Many noteworthy peaks can be realized, and they are listed in Table $\mathbf{1}$ in order of the latency time (t) after the stimulation start. The significant peaks are indicated by asterisks $(*)$, and relevant comments and data already reported by other investigators are also included in the 
Table 1. Spectrum peaks of ERP in Figure 2.

\begin{tabular}{|c|c|c|c|c|}
\hline Latency & Using face portrait & Using geometric pattern & Reported by others & \\
\hline (ms) & $\mathrm{F}$ & G & & \\
\hline 80 & & & 80 [15] & \\
\hline 100 & $\mathrm{~F}_{\mathrm{z}}(\mathrm{N})^{*}, \mathrm{P}_{\mathrm{z}}(\mathrm{N})^{*}$ & & N (100) [2], 110 [1] & (first eliciting) [9] \\
\hline 130 & & $\mathrm{O}_{2}(\mathrm{~N})^{*}, \mathrm{~F}_{\mathrm{z}}(\mathrm{P})^{*}, \mathrm{P}_{\mathrm{z}}(\mathrm{P})$ & & \\
\hline $160-170$ & $\mathrm{~T}_{4}(\mathrm{P}) \mathrm{F}_{\mathrm{z}}(\mathrm{P})^{*}, \mathrm{P}(\mathrm{z})^{*}$ & & N (170) [2] & (face-cognition) [2] \\
\hline $180-190$ & & $\mathrm{O}_{2}(\mathrm{P})^{*} \mathrm{~F}_{\mathrm{z}}(\mathrm{N})^{*}, \mathrm{P}_{\mathrm{z}}(\mathrm{N})^{*}$ & & \\
\hline $200-210$ & $\mathrm{~T}_{4}(\mathrm{~N}) \mathrm{F}_{\mathrm{z}}(\mathrm{N})^{*}, \mathrm{P}_{\mathrm{z}}(\mathrm{N})^{*}$ & & N (200) [1] & \\
\hline 250 & & $\mathrm{O}_{2}(\mathrm{~N})^{*}$ & & \\
\hline \multirow[t]{2}{*}{$280-300$} & $\mathrm{O}_{2}(\mathrm{~N})^{*} \mathrm{~T}_{4}(\mathrm{~N})^{*} \mathrm{~F}_{\mathrm{z}}(\mathrm{N})^{*} \mathrm{P}_{\mathrm{z}}(\mathrm{N})^{*}$ & $\mathrm{~F}_{\mathrm{z}}(\mathrm{N})^{*}, \mathrm{P}_{\mathrm{z}}(\mathrm{N})^{*}$ & $\mathrm{P}(290)[1]$ & \\
\hline & $\mathrm{F}_{\mathrm{z}}(\mathrm{N}), \mathrm{P}_{\mathrm{z}}(\mathrm{N})$ & & P (300) [12] & (attention) [9] \\
\hline $330-370$ & $\mathrm{O}_{2}(\mathrm{P})^{*} \mathrm{~T}_{4}(\mathrm{P})^{*} \mathrm{~F}_{\mathrm{z}}(\mathrm{P})^{*} \mathrm{P}_{\mathrm{z}}(\mathrm{P})^{*}$ & $\mathrm{~T}_{4}(\mathrm{P})^{*} \mathrm{~F}_{\mathrm{z}}(\mathrm{P})^{*} \mathrm{P}_{\mathrm{z}}(\mathrm{P})^{*}$ & $\mathrm{P}(350)[1]$ & \\
\hline $400-430$ & $\mathrm{~F}_{\mathrm{z}}(\mathrm{N})^{*} \mathrm{P}_{\mathrm{z}}(\mathrm{N})^{*}$ & $\mathrm{~F}_{\mathrm{z}}(\mathrm{N})^{*}, \mathrm{P}_{\mathrm{z}}(\mathrm{N})^{*}$ & & \\
\hline $470-490$ & $\mathrm{~F}_{\mathrm{z}}(\mathrm{P})^{*}$ & $\mathrm{O}_{2}(\mathrm{~N})^{*}$ & & \\
\hline
\end{tabular}

Asterisk * indicates significant peaks.

table.

Most of the dominant peaks corresponding to the geometrical pattern $(\mathrm{G})$ at $\mathrm{O}_{2}$ site agree well with previously reported findings. For instance, those peaks described as the first elicited peak at $100 \mathrm{~ms}$ of $(\mathrm{F})$ at $\mathrm{F}_{\mathrm{z}}$ and $\mathrm{P}_{\mathrm{z}}[1,2]$, and also the face perception peak at $170 \mathrm{~ms}$ [13,16-18], and the attention index peak at $300 \mathrm{~ms}$ [12] were also observed in the present study both in (F) and (G). In addition, new peaks around N130, N180.190, N250, N400.430, and N470 were found.

In Figure 3, the ERP result of the oddball un-indicated (U) condition is also compared between the face (F, orange) and the geometrical pattern (G, green). The most remarkable difference between (I) and (U) is that the indicated display (I) induced significant peaks. But in (U), most peaks before $400 \mathrm{~ms}$ were degraded or diminished.

However, after then, several peaks that could not be observed in Figure 2 were likely to appear, such as those at 400, 520.540, and $700 \mathrm{~ms}$, as shown in Figure 3. To be noted is that these peaks appear after $0.5 \mathrm{sec}$ figure presentation.

\section{DISCUSSION}

Recently many ERP investigations have adopted multipoints observation methods, using 128 - 256 electrodes for obtaining fine potential distributions on the scalp [5].

Anyhow, most of them showed gradually changing among the electrodes, and then provided smooth potential distribution in space around a few maximum points that are mostly corresponding to the above indicated four points of $\mathrm{O}_{2}, \mathrm{~T}_{4}, \mathrm{~F}_{\mathrm{z}}$ and $\mathrm{P}_{\mathrm{z}}$. Accordingly we took a dominant view among this four points ERP data as shown in Figures 2 and 3. The primary limitation of ERP experiments is that signal data must be collected from electrodes attached onto the head, and the direct correspondence between the signal and the activity of each brain area can be difficult to determine. However as is shown in Figures 2 and 3, the electrodes do not provide the same averaged signal; rather, they provide specific waveforms and amplitudes reflecting the activity of neighboring brain areas, as shown. For this reason, we selected the 4 electrode points, $\mathrm{O}_{2}, \mathrm{~T}_{4}, \mathrm{P}_{\mathrm{z}}$, and $\mathrm{F}_{\mathrm{z}}$, corresponding to the key brain areas involved in the two-pathway model, which had been also adopted by Bentin et al. [2] as the key points, with some additional electrodes.

The site of the reference potential electrode should also be considered. In this experiment, it was set at the linked earlobes, and some signal depression at $\mathrm{O}_{2}$, and $\mathrm{T}_{4}$ may have been induced by their proximity to the reference [19]. Notwithstanding, in Figure 2, remarkably strong peaks were observed at N130 and P170 for (G) and $(F)$. The placement of a reference potential electrode is an electrostatic potential problem in volumetric brain conduction, and doesn't matter of the subjects' $(F)$ and (G) values. Accordingly, differences between the peak heights at $\mathrm{O}_{2}, \mathrm{~T}_{4}, \mathrm{P}_{\mathrm{z}}$, and $\mathrm{F}_{\mathrm{z}}$ in Figures 2 and $\mathbf{3}$ should be considered intrinsic.

Event-related potential (ERP) method possesses fine time resolution of less than $10 \mathrm{~ms}$ [11]. Accordingly, we applied ERP to the present analysis of this perception 
process.

In case of face stimuli (F) in Figure 2, N100 first appears significantly at $\mathrm{P}_{\mathrm{z}}$ and $\mathrm{F}_{\mathrm{z}}$, but for geometric stimuli (G), N130 appears at $\mathrm{O}_{2}$. This finding supports the existence of two different pathways and suggests that an initial gate of rapid pathway 1 , for faces, is near $P_{z}$ and $F_{z}$, which is considered to be the thalamus or amygdala in the limbic system,

Next the second initial gate of pathway 2, for geometric patterns, is the occipital visual cortex near $\mathrm{O}_{2}$; a little bit later. A previous report has described this gate as the so-called N170 peak [13,20], and dominantly related to face perception and originates in the occipito-temporal cortex. But, in the present study, we observed the peak at an earlier time of $100.130 \mathrm{~ms}$.

Most of the significant peaks in Figure 2 are listed in Table 1, indicating that after the start of both pathways, (F) and (G) were detected by different electrodes up to $250 \mathrm{~ms}$, [21] i.e., (F) elicits activity preferentially at $\mathrm{T}_{4}$, and $(\mathrm{G})$ prefers $\mathrm{O}_{2}$. This finding is the second in this study to provide evidence supporting the two-pathway system, with pathway 1 for facial recognition activating the limbic system, and pathway 2 for geometric pattern recognition constrained to the occipito-temporal system.

How is one pathway gate selected and the other closed? When the face image (F) stimulates the retina, visual information travels to the thalamus at $100 \mathrm{~ms}$, and the amygdala is then instantaneously activated. Simultaneously, the second pathway gate to the occipital visual cortex is closed, leading to no detectable ERP in the $\mathrm{O}_{2}$ region.

This situation may be understood simply by observing a typical childhood behavior that something fear glance, at once escape without any looking.

After 300 ms latency, common peaks can be observed in Figure 2 and also in Table 1, in which the same electrodes $\mathrm{F}_{\mathrm{z}}(\mathrm{N})^{*}$ and $\mathrm{P}_{\mathrm{z}}(\mathrm{N})^{*}$ appear in both of the $(\mathrm{F})$ and (G) columns [22]. Accordingly, the pathways may be unified at this time point in the orbito-frontal association cortex $\left(\mathrm{F}_{\mathrm{z}}\right)$ and the sensory association cortex $\left(\mathrm{P}_{\mathrm{z}}\right)$, probably in the stage of conscious recognition because of the attention index notice [9] in Table 1. These kinds of information processing systems and the distributed areas in the brain have been discussed in several previous reports [1-4].

In light of our results, the system under investigation may be summarized and attempted in a diagram expression as depicted in Figure 4.

The ERP waveforms for the un-indicated condition (U) of the oddball method are shown in Figure 3. In comparison with Figure 2, which depicts the indicated condition (I), two points are remarkable. The first is that (U) demonstrates less prominent peak features than (I), likely due to the extent of attention. In the case of $(G)$ in

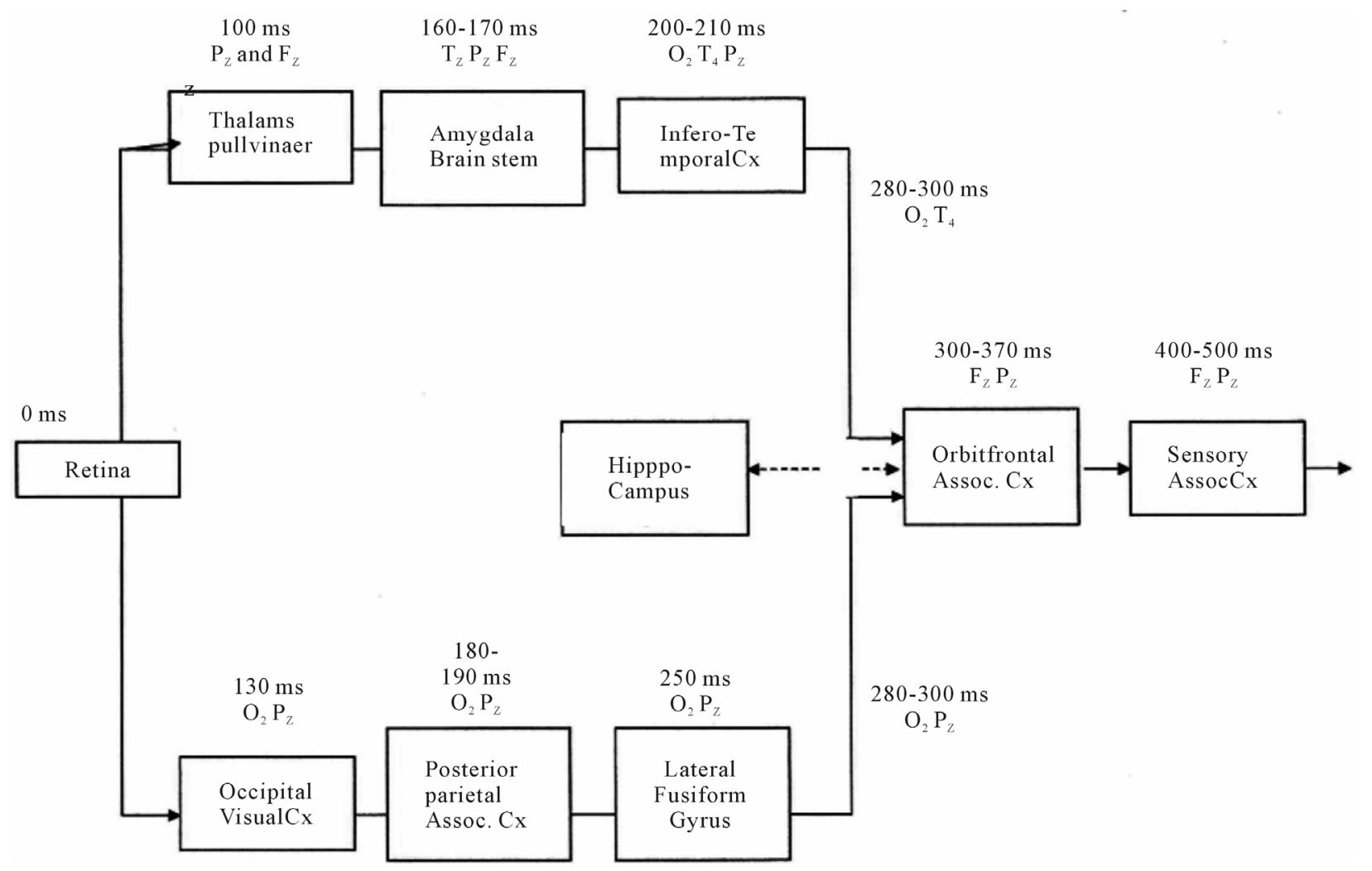

Figure 4. A proposed diagram of the human visual perception process. 
Figure 3, the waveform is almost smooth without any peaks, especially in the range of 300 - $380 \mathrm{~ms}$ (around the attention index in Table 1), which suggests that the subjects paid less attention to un-indicated images and patterns. The second is that after $400 \mathrm{~ms}$, some gradual peaks appear in Figure 3, which may indicate that less initial attention is related to later intention of reconfirmations.

\section{CONCLUSION}

There is a significant difference in the initial transition process between the two pathways for face and pattern perception, and then they are combined in a unified pathway for the recognition process. The results of the present experiment support this two-pathway model of visual perception.

\section{ACKNOWLEDGEMENTS}

The experiments have been carried at the electrical laboratory in the College of Industrial Technology with kind supports on the electronic circuits design by Prof. K. Satoh, and also with hearty collaborations of many laboratory students. We are also much indebted to the kind advices of Physiology and Biosignaling laboratory (Osaka Univ.) stuffs of Profs. H. Sawai, T. Miyoshi, and also under general auspices of Prof, Yutaka Fukuda. Regarding the ERP observation techniques, valuable and kind comments were provided by Prof. H. Nittono (Hiroshima Univ.) for the reference electrode, and by Prof. Y. Sakai (Gunnma Univ.) for the MRCP background. Many thanks are due.

\section{REFERENCES}

[1] Allison, T., Puce, A., Spencer, D.D. and McCarthy, G., (1999) Electrophysiological studies of human face perception. I: Potentials generated in occipito-temporal cortex by face and non-face stimuli. Cerebral Cortex, 9, 415-460. doi:10.1093/cercor/9.5.415

[2] Bentin, S., Allison, T., Puce, A., Perez and McCarthy, E.G. (1996) Electrophysiological studies of face perception in humans. Journal of Cognitive Neuroscience, 86, 551-565. doi:10.1162/jocn.1996.8.6.551

[3] Haxby, J.V., Hoffman, E.A. and Gobbini, M.I. (2000) The distributed human neural system for face perception. Trends in Cognitive Sciences, 4, 223-233. doi:10.1016/S1364-6613(00)01482-0

[4] Sasaki, H. (2009) Cortical and sub-cortical processing of color: A dual processing mode of visual inputs. In: Sukusevich D. and Matikas, P., Eds., Color Perception Physiology and Analysis, Nova Science Pub. Inc., New York.

[5] Foxe, J.J. and Simpson, G.V. (2002) Flow of activation from V1 to frontal cortex in humans. A frame work for defining early visual processing. Experimental Brain Research, 142, 139-150. doi:10.1007/s00221-001-0906-7

[6] Haxby, J.V., Hoffman, E.A. and Gobbini, M.I. (2002)
Human neural systems for face recognition social communications. Biological Psychiatry, 51, 59-67. doi:10.1016/S0006-3223(01)01330-0

[7] Papez, J.W. (1937) A proposed mechanism of emotion. Archives of Neurology and Psychiatry, 38, 725-743.

[8] Miller, G.A., Lutzenberger, W. and Elbert, T. (1991) The linked reference issue in EEG and ERP recording. Journal of Psychophysiology, 5, 273-276.

[9] Adolphs, R. (2002) Neural systems for recognizing emotion. Current Opinion in Neurobiology, 12, 169-177. doi:10.1016/S0959-4388(02)00301-X

[10] Sanei, S. and Chambers, J. (2007) EEG signal processing. Chapter 3, John Wiley \& Sons Ltd., Oxford.

[11] Aoki, R., Okamoto, S., Sakimoto, T., Yoshida, K. and Sasaki, H. (2009) Event related potentials elicited by facial recognition. Neuroscience Research, 65, s40. doi:10.1016/j.neures.2009.09.039

[12] Duncan-Johnson, C.C. and Donchin, E. (1977) On qualifying surprise: The variation of ERP with subjective probability. Psychophysiology, 14, 456-467. doi:10.1111/j.1469-8986.1977.tb01312.x

[13] Rossion, B. and Jacques, C. (2008) Does physical interstimulus variance account for early electro-physiological face sensitive responses in the human brain? Ten lessons on the N170. Neuroimage, 39, 1959-1979. doi:10.1016/j.neuroimage.2007.10.011

[14] Kajiwara, K. (1984) Actresses in French Cinema, Cinealbum No111, Haga Shoten, Tokyo.

[15] Pizzagalli, D., Regard, M. and Lehman, D. (1999) Rapid emotional face processing in the human right left brain hemispheres: An ERP study. Neuroreport, 10, 2691-2698. doi:10.1097/00001756-199909090-00001

[16] Jeffreys, D.A. (1996) Evoked studies of face and object processing. Visual Cognition, 3, 1-38. doi:10.1080/713756729

[17] Joyce, C.A. (2006) Early selection of diagnostic facial information in the human visual cortex. Vision Research, 46, 800-813. doi:10.1016/j.visres.2005.09.016

[18] Righart, R. and deGelder, B. (2008) Rapid influence of emotional scenes on encoding of facial expressions: An ERP study. Social Cognitive \& Affective Neuroscience, 3, 270-278. doi:10.1093/scan/nsn021

[19] Nunez, P. L. and Srinivasan, R. (2006) The neuronphysics of EEG. 2nd Edition, Oxford University Press, New York.

[20] Thierry, G., Martin C.D., Downing P. and Pegna, A.J. (2007) Controlling for inter-stimulus perceptual variance abolishes N170 face selectivity. Nature Neuroscience, 10, 505-511.

[21] Federmeier, K.D. and Kutas, M. (2002) Pictures the difference; electrophysiological investigations of picture processing in the two cerebral hemispheres. Neuropsychologia, 40, 730-747. doi:10.1016/S0028-3932(01)00193-2

[22] Polich, J. (2007) Updating P300: An integrative theory of P3a P3b. Clinical Neurophysiology, 118, 2128-2148. doi:10.1016/j.clinph.2007.04.019 